\title{
Correspondence between assemblages of coral reef fishes and gradients of water motion, depth, and substrate size off Puerto Rico
}

\author{
M. Angela McGehee \\ Department of Marine Sciences, University of Puerto Rico, PO Box 908 Lajas, Puerto Rico 00667, USA
}

\begin{abstract}
Censuses were taken at 8 coral reefs in southwest Puerto Rico to identify assemblages of fishes and to determine whether water motion, depth, and substrate were correlated with fish distribution and abundance. Each reef was sampled by recording species and abundance of fishes and substrate sizes within quadrats placed at different depths (from reef crest to an average of $6 \mathrm{~m}$ deep) along transects placed on forereefs and backreefs. Water motion was examined by measuring the amount of dissolution of plaster-of-Paris blocks which gave a relative index of the degree of water movement within and among reefs. Data collected on 14 fish species and measurements of water motion, degree of reef slope, and 4 sizes of substrate over 32 transects were analyzed to identify species groups and examine ecological correlates. The analyses indicated 3 species assemblages which differed in distribution and abundance within reefs (backreef, shallow forereef, and deep forereef) and among reefs (nearshore, intermediate, and offshore reefs). Similarly, water movement, depth, reef slope and substrate size occurred as gradients that differed significantly within and among reefs. Fishes in Assemblage 1 included primarily Ophioblennius atlanticus, Thalassoma bifasciatum, Stegastes dorsopunicans, and Microspathodon chrysurus. These species were most common on the shallow forereef, particularly at offshore reefs (those farthest from land); these sites were characterized by a high degree of water motion, gentle forereef slope, and boulder-sized substrate. Assemblage 2 species included Stegastes planifrons, Hypoplectrus chlorurus, and Holocentrus rufus. These fishes were most abundant on the deep forereef, especially at nearshore reefs (sites closest to land), which were typified by relatively low water movement, steep slope, and smaller substrate sizes. Fishes in Assemblage 3 (Stegastes leucostictus and Malacoctenus macropus) were most numerous in the backreef where water motion, slope inclination, and substrate sizes were minimal compared with the forereef. While biological variables are undoubtedly important in determining species distributions, the different assemblages were found to be correlated with variations in water motion, depth, and substrate type. These 3 physical variables occurred as interrelated gradients, but the analyses suggested that water movement energy was the environmental factor most strongly associated with species distributions.
\end{abstract}

KEY WORDS: Fish assemblages - Coral reefs - Physical gradients - Water motion · Depth - Substrate size

\section{INTRODUCTION}

Most coral reefs do not have a uniform structure and can be divided into regions or zones, such as backreef, reef crest, forereef slope, etc. (Goreau 1959). Similarly, animals and plants do not appear to be distributed evenly throughout coral reefs. Within a reef, numbers and types of organisms may vary with zonation; certain species or assemblages of species appear to be characteristic of certain zones (e.g. Goreau 1959, Hiatt \& Strasburg 1960, Jones 1968, Emery 1973, Goldman \&
Talbot 1976, Van den Hoek et al. 1978, Bradbury \& Young 1981, Bell \& Galzin 1984, Russ 1984a, b, Alevizon et al. 1985, Galzin \& Legendre 1987, Green et al. 1987, Harmelin-Vivien 1989). The type and location of a reef seem to affect the flora and fauna present, and these may differ from other reefs in the same area (McGehee 1991).

While biological variables, such as habitat preference and competition, undoubtedly affect community structure, the distributions of organisms are often mediated by their relationships with the physical 
environment (reviewed in Sale 1991). Various studies have indicated that physical variables, in particular current, depth, and substrate, have an important influence on the distributions of aquatic organisms (e.g. Gorman \& Karr 1978, Waldner 1980, Bradbury \& Young 1981, Schlosser 1982, Williams 1982, Russ 1984a, b, Green et al. 1987). These 3 factors occur as interrelated gradients on reefs (Friedman \& Saunders 1978, James 1983, Huston 1985, Denny 1988). Many species are associated with particular parts of gradients of environmental factors (coenoclines); some species may occupy only a narrow range within an environmental gradient because of limited tolerance to the physical environment or because of interactions with other species within the gradient (reviewed by Whittaker 1975). Community structure in the marine environment may be strongly influenced by individualistic population responses to coenoclines (Boesch 1977, Weinstein et al. 1980, Rakocinski et al. 1992). The range of tolerance to gradients of water motion, depth, and substrate sizes on coral reefs may vary from species to species. Little research has been done to measure these physical factors empirically and to relate these data to the abundance and distributions of reef fishes on a large scale.

The purpose of this study was to determine whether coral reef fishes in Puerto Rico coexist in assemblages whose compositions are correlated with various physical factors. Gradients of water motion, depth, and substrate sizes were measured quantitatively and the results examined for correspondences with fish community structure, both within and among coral reefs. An independent study conducted over the same time and within the same area as the present investigation found no significant temporal differences in fish species assemblages (Turingan \& Acosta in press). Therefore, the present study concentrated on the spatial relationships of coral reef assemblages and assumed that they were stable at least over the period of time that the study was conducted.
A species often is associated with the same type of habitat in widely separated geographic areas (Waldner \& Robertson 1980). This observation suggests that particular species may be expected to recur in areas characterized by certain coenoclines. Correlations between species distributions and environmental gradients can be useful in predicting the presence or absence of fishes at a given location. Such predictions may have important implications in such areas as fisheries management (e.g. locating commercial species), assessing impact of and recovery from reef destruction, and construction of artificial reefs.

\section{MATERIALS AND METHODS}

Study sites. Eight coral reefs near La Parguera, southwest Puerto Rico (Table 1, Fig. 1), were sampled in 1988 and 1989. The reefs varied in distance from land and degree of exposure to wind and currents. The prevailing wind and current were from the east to southeast, so that the south sides of the reefs, and particularly the southernmost reefs, received the greatest exposure. At all sites, the long axis of the reef was oriented from east to west. The forereef was on the south side, and the backreef was on the north side of the reef.

Three of the southernmost reefs (Reefs 1, $2 \& 3$ ) were emergent shelf reefs (Morelock et al. 1977) and were roughly crescent-shaped, with much of the reef crest rising above the water. The easternmost site (Reef 4) was a completely submerged patch reef (minimum depth about $3 \mathrm{~m}$ ) where water moved easily over the top between forereef and backreef. In contrast, there was little exchange of water between front and back of emergent reefs except at the east and west ends. Emergent reefs were characterized by shallow, gently sloping backreefs, and forereefs with comparatively steeper slopes down to greater depths. The submerged

Table 1 Descriptions of reefs, number of depth strata, and number of $1 \times 6 \mathrm{~m}$ quadrats investigated at study sites off the southwest coast of Puerto Rico. Reef 4 was a submerged reef. All other sites were emergent reefs

\begin{tabular}{|c|c|c|c|c|c|c|c|c|c|}
\hline \multirow{2}{*}{$\begin{array}{c}\text { Reef } \\
\text { number }\end{array}$} & \multirow{2}{*}{$\begin{array}{c}\text { Dates } \\
\text { sampled }\end{array}$} & \multirow{2}{*}{$\begin{array}{c}\text { Category } \\
\text { of reef }\end{array}$} & \multirow{2}{*}{$\begin{array}{c}\text { Approx. } \\
\text { distance } \\
\text { from land } \\
(\mathrm{km})\end{array}$} & \multicolumn{3}{|c|}{ Forereef } & \multicolumn{3}{|c|}{ Backreef } \\
\hline & & & & $\begin{array}{c}\text { Depth } \\
\text { range } \\
\text { (m) }\end{array}$ & $\begin{array}{l}\text { No. of } \\
\text { strata }\end{array}$ & $\begin{array}{c}\text { No. of } \\
\text { quadrats }\end{array}$ & $\begin{array}{c}\text { Depth } \\
\text { range } \\
\text { (m) }\end{array}$ & $\begin{array}{l}\text { No. of } \\
\text { strata }\end{array}$ & $\begin{array}{l}\text { No. of } \\
\text { quadrats }\end{array}$ \\
\hline 1 & May, Aug 1988 & Offshore & 3.7 & $1-5$ & 4 & 16 & $0-2$ & 2 & 8 \\
\hline 2 & Aug, Sep 1988 & Offshore & 2.8 & $1-5$ & 4 & 16 & $0-2$ & 2 & 8 \\
\hline 3 & Apr, Aug 1988 & Offshore & 3.5 & $1-5$ & 4 & 16 & $0-2$ & 2 & 8 \\
\hline 4 & Oct, Nov 1988 & Intermediate & 3.7 & $4-10$ & 6 & 24 & $4-10$ & 6 & 24 \\
\hline 5 & Aug 1988 & Intermediate & 2.0 & $1-6$ & 5 & 20 & $0-2$ & 2 & 8 \\
\hline 6 & Sep, Oct 1988 & Intermediate & 1.7 & $0-3$ & 3 & 12 & $0-2$ & 2 & 8 \\
\hline 7 & Sep 1988 & Nearshore & 1.5 & $0-6$ & 6 & 24 & $0-2$ & 2 & 8 \\
\hline 8 & Dec 1988, Jan 1989 & Nearshore & 0.9 & $0-6$ & 6 & 24 & $0-2$ & 2 & 8 \\
\hline
\end{tabular}


Fig. 1. Location of the 8 coral reef study sites investigated in southwest Puerto Rico

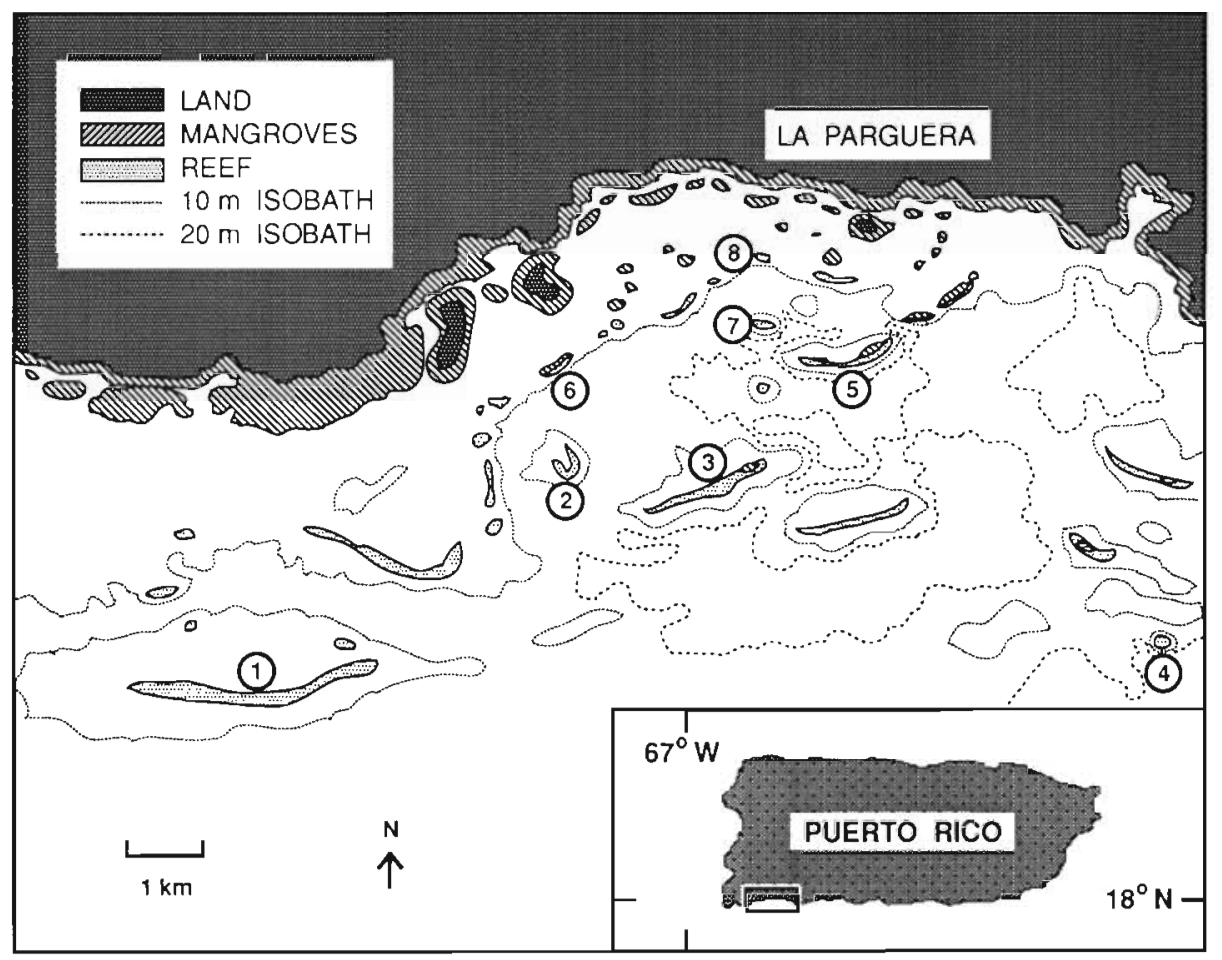

reef had forereef characteristics similar to emergent sites, but the backreef was nearly identical to the forereef in slope and depth

The next reefs to the north (Reefs $5 \& 6$ ) were both crescent-shaped emergent reefs. The northernmost sites (Reefs $7 \&$ 8) were both large patch reefs emergent at low tide. The reef crests were seldom more than about 20 to $30 \mathrm{~cm}$ below the surface at high tide. The tidal cycle in southern Puerto Rico is semidiurnal; the range is usually less than $0.5 \mathrm{~m}$ and rarely exceeds $1 \mathrm{~m}$.

The reefs were divided into 3 generalized groups (Table 1). Emergent sites were grouped according to distance from land. The southernmost reefs (1, $2 \& 3)$, which were farthest from land, were termed the offshore reefs. The next 2 sites to the north, Reefs $5 \& 6$, were called the intermediate reefs. The 2 sites closest to land, Reefs $7 \& 8$, were designated as the nearshore reefs. The submerged reef, Reef 4 , was included with the intermediate reefs because of similarities in biological and physical characteristics.

Sampling methods. Methods were the same as described in McGehee (1992). Reefs were surveyed using transects modified from procedures outlined by Dana (1976). Transect lines were placed perpendicular to the long axis of the reef from the shallowest depth that an observer could safely investigate to a maximum of $6 \mathrm{~m}$ below that depth. Heavy surge made sampling dangerous at a depth of 0 to $1 \mathrm{~m}$ at Reefs $1,2,3 \& 5$. Each reef had 4 transect lines, 2 on the forereef and 2 on the backreef (Fig. 2). The length of each reef was visually divided into thirds, and transect lines were placed at the division between each third. Each transect was divided into strata; a stratum represented a depth change of $1 \mathrm{~m}$ (e.g. from the $3 \mathrm{~m}$ isobath to the $4 \mathrm{~m}$ isobath equaled 1 stratum). Each transect was sampled once.

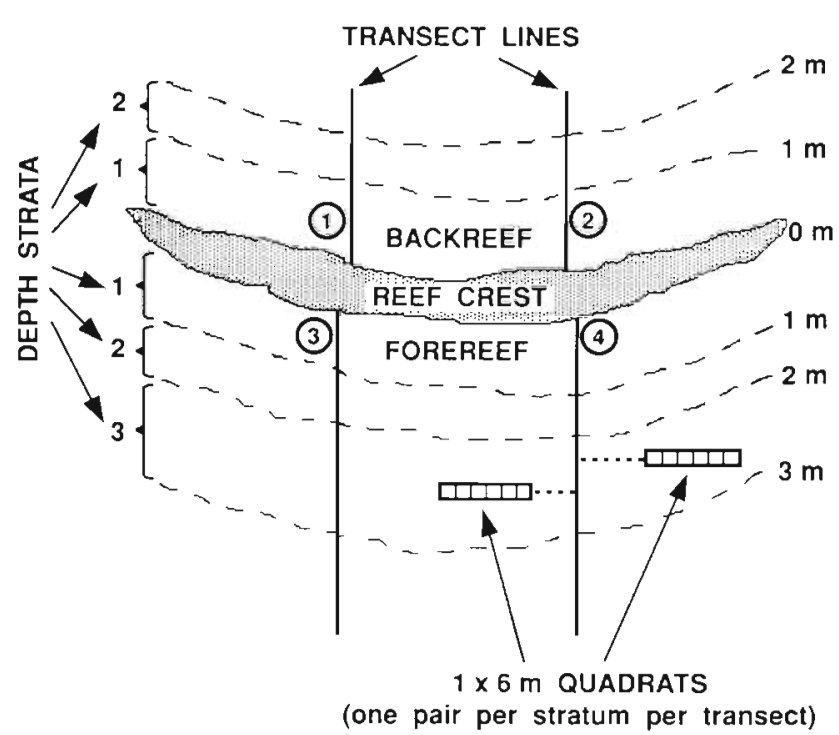

Fig. 2. Diagram of a reef showing placement of transect lines (numbered) and randomly located quadrats (not drawn to scale). Each stratum contained 4 quadrats. The number of strata varied from reef to reef 
On each transect, 2 quadrats were placed within each stratum, 1 quadrat on either side of the transect line. Each quadrat was placed by choosing a random point along the transect line within the stratum and swimming 0 to 30 finkicks in a direction perpendicular to the line. The number of kicks was selected at random using a list of random numbers carried on an underwater writing slate. Thus, each stratum was intersected by 2 transect lines, resulting in a total of 4 quadrats per stratum. Sampling was discontinued at a distance of approximately $100 \mathrm{~m}$ north and south of the reef crest. The quantity of strata and quadrats varied according to the profile of the individual reef within the $100 \mathrm{~m}$ limits (Table 1 ). The forereefs included from 3 to 6 strata. Backreefs consisted of 2 strata at all emergent sites and 6 strata at the submerged reef.

Quadrats had a width of $1 \mathrm{~m}$ and a length of $6 \mathrm{~m}$. These were placed with the long axis perpendicular to the transect line (Fig. 2). Each quadrat was assessed 1 square meter at a time by placing a square wire frame ( $1 \mathrm{~m}$ on each side) on the substrate, recording the data on a slate, then flipping the wire square over and repeating the process until 6 consecutive square meters had been surveyed. The number of individuals of each fish species inside or above the square meter was counted within the first 2 min after the wire frame was placed, and then substrate characteristics were assessed. Substrate particle sizes were estimated for inclusion into 1 of 4 categories modified after the Wentworth grade classification (Buchanan \& Kain 1971): boulder (>256 mm), cobble (64 to $256 \mathrm{~mm}$ ), pebble ( 4 to $64 \mathrm{~mm}$ ) and sand $(<4 \mathrm{~mm})$. The area covered by each of the 4 substrate types was estimated for every square meter in a quadrat. Coverage was estimated without regard to living substrates, e.g. boulder corals were included in the estimates of boulder coverage.

The accuracy of substrate cover estimates was tested using the following procedure. The amount of cover of each substrate size was estimated within the $1 \mathrm{~m}^{2}$ wire frame placed on a reef. A $1 \mathrm{~m}^{2}$ grid with a mesh size of $1 \mathrm{~cm}^{2}$ was then placed over the wire frame, and the actual number of square centimeters covered by each type of substrate was counted. There was a high correlation between estimates and actual counts of substrate cover $\left(R^{2}=0.9725, n=20\right)$. Estimates differed from actual values by no more than $5 \%$.

Water movement was measured using plaster-ofParis blocks (Doty 1971). Blocks of known weight were placed as concurrently as possible at stations of predetermined depths on the 8 reefs and retrieved after $24 \mathrm{~h}$. Weight loss due to plaster dissolution provided a relative index of the degree of water movement between stations. The stations were established along the approximate midline of each reef perpendicular to the long axis. At the 7 emergent reefs, a station was located in the 1 to $2 \mathrm{~m}$ stratum on the backreef and in the 1 to $2 \mathrm{~m}$ and 4 to $5 \mathrm{~m}$ strata on the forereef, except for Reef 6 , where the forereef did not extend below $3 \mathrm{~m}$ within the area sampled. At the submerged reef reef (4), stations were established in the 4 to $5 \mathrm{~m}$ and 7 to $8 \mathrm{~m}$ strata on both forereef and backreef. Four plaster-of-Paris blocks were placed at each station. The blocks measured $3 \times 3 \times 5 \mathrm{~cm}$ and weighed 24 to $29 \mathrm{~g}$. They were attached with rubber bands and twistties to a $30 \times 30 \mathrm{~cm}$ square of wire mesh bent around the blocks to make a protective cage. At each station, the cage was tied to the base of a buoy line attached to a concrete block.

Before and after immersion, the blocks were sundried for $6 \mathrm{~h}$ and air-dried for $6 \mathrm{~d}$ in an air-conditioned (low humidity) room. The blocks were weighed several times on a digital balance before and after immersion, until a stable weight to the nearest $0.1 \mathrm{~g}$ was recorded. Blocks were calibrated as described by Doty (1971).

Data analysis. Data on abundance of species by quadrat were examined using hierarchical cluster analysis (unweighted pair groups method using arithmetic averages) to identify species assemblages (Gauch 1982). Since data on physical and biological parameters did not meet the criteria for parametric statistics (normality and homogeneity of variances), these data were evaluated to detect differences within and among reefs using nonparametric analyses, including the Mann-Whitney $U$-test, Kendall rank correlation coefficient, Kruskal-Wallis test, and Dunn's multiple comparison applied to Kruskal-Wallis rank sums. All values were corrected for ties. An alpha of 0.05 was taken to indicate statistical significance, and all tests were 2-tailed.

Detrended correspondence analysis (DCA) was performed using BIO STAT (Pimentel \& Smith 1986). This analysis is a powerful multivariate technique used to make 2-dimensional plots of species and of sites to evaluate the similarity of community structures (Gauch 1982). In general, scores for both species and sample sites are determined jointly in the same ordination space by their weighted averages. Species with similar scores tend to co-occur; sites with similar scores have similar species compositions. Thus, comparisons of score displays for species and sites may be used to identify their joint associations. Additionally, environmental information can be superimposed on displays of site scores to indicate ecological correlates of community structure (Rakocinski et al. 1992). The results of the previous tests (cluster analysis, Kruskal-Wallis, etc.) were needed for delineation of groups of species and sites related by habitat on the DCA plots. Conclusions drawn from the previous analyses were used to help identify gradients of environmental factors associated with the axes of the DCA plots. 


\section{RESULTS}

\section{Species and assemblages}

In the 8 reefs investigated near La Parguera, 71 species of fishes were recorded, plus 4 groups of fishes which were identified only to family. Omitted from analyses were all species which were present in $10 \%$ or less of the quadrats (i.e. less than 23 of the 232 total quadrats). These species were not sufficiently abundant for subsequent analyses to indicate any significant relationships. A few other groups (e.g. Sparidae, Gobiosoma sp.) were eliminated due to uncertainty of identification. As a result, 14 fish species were analyzed.

The results of the cluster analysis indicated several distinct species groups (Fig. 3). Four fishes, including redlip blenny Ophioblennius atlanticus (Valenciennes), bluehead wrasse Thalassoma bifasciatum (Bloch), dusky damselfish Stegastes dorsopunicans (Poey), and yellowtail damselfish Microspathodon chrysurus (Cuvier), appeared to be closely associated and were

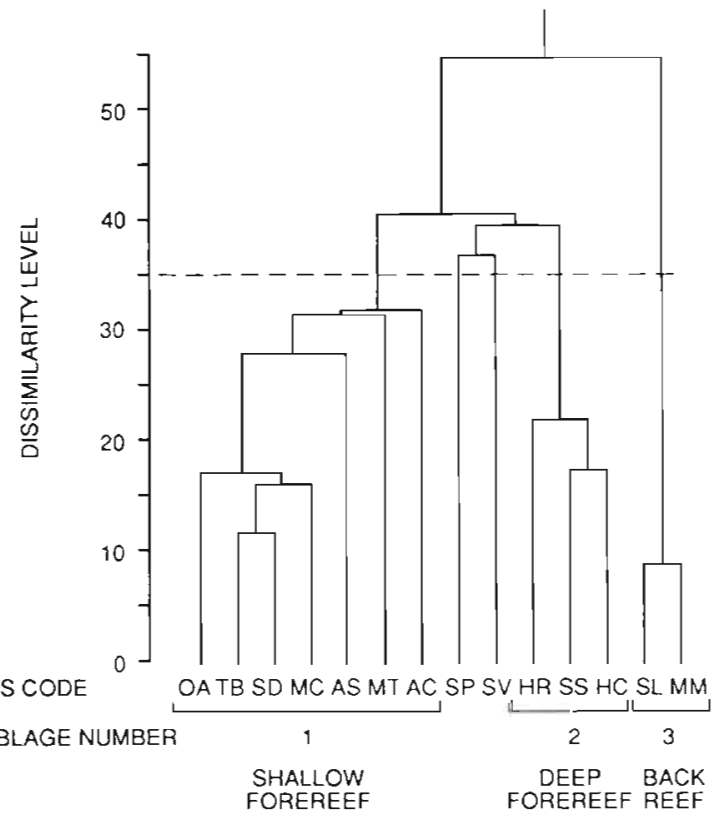

Fig. 3. Cluster analysis dendrogram showing associations of 14 fish species censused at 8 coral reefs in southwest Puerto Rico. Species groups were designated below the dashed line. Each species is represented by a 2-letter code as follows: $\mathrm{AC}=$ blue tang Acanthurus coeruleus, AS = doctorfish Acanthurus chirurgus, $\mathrm{HC}=$ yellowtail hamlet Hypoplectrus chlorurus, $\mathrm{HR}=$ squirrelfish Holocentrus rufus, $\mathrm{MC}=$ yellowtail damselfish Microspathodon chrysurus, $\mathrm{MM}=$ rosy blenny Malacoctenus macropus, MT = saddled blenny Malacoctenus triangulatus, $\mathrm{OA}=$ redlip blenny Ophioblennius atlanticus, $\mathrm{SD}=$ dusky damselfish Stegastes dorsopunicans, $\mathrm{SL}=$ beaugregory Stegastes leucostictus, $\mathrm{SP}=$ bicolor damselfish Stegastes partitus, $\mathrm{SS}=$ threespot damselfish Stegastes planifrons, $\mathrm{SV}=$ cocoa damselfish Stegastes variabilis, $\mathrm{TB}=$ bluehead wrasse Thalassoma bifasciatum designated as Assemblage 1. Less strongly associated with Assemblage 1 were blue tang Acanthurus coeruleus Schneider, saddled blenny Malacoctenus triangulatus Springer, and doctorfish Acanthurus chirurgus (Bloch). These latter 3 species were classified as secondary members of the assemblage.

Three species, threespot damselfish Stegastes planifrons Cuvier, yellowtail hamlet Hypoplectrus chlorurus (Valenciennes), and squirrelfish Holocentrus rufus (Walbaum), formed another close group and were termed Assemblage 2. Bicolor damselfish Stegastes partitus Poey, and cocoa damselfish Stegastes variabilis (Castlenau), occupied space on the dendrogram between Assemblages $1 \& 2$ but did not appear to be closely associated with either species group.

Beaugregory Stegastes leucostictus Müller \& Troschel, and rosy blenny Malacoctenus macropus (Poey), clearly formed a group separate from the other species and were designated as Assemblage 3. These 2 fishes were the only ones found in significantly greater numbers in the backreef environment (Table 2). The other 12 species were all recorded in higher numbers on forereefs, although this difference was significant only for the primary members of Assemblage 1 and for Assemblage 2 (Table 2).

The groups described above became evident in the cluster analysis at level 35 (Fig. 3). Division at a higher level (e.g. 45) separated species into 2 groups associated with forereefs or backreefs. At a lower level (e.g. 25), the primary assemblages were still intact; only the secondary members of Assemblage 1 became disassociated from their group. Groups divided at level 35 resulted in the same assemblages indicated by other analyses reported in McGehee (1991).

Numbers of fish in each of the 14 species were analyzed for correlation with depth strata as an indication of changes in abundance with depth (Table 2). The fishes of Assemblage 3 (Stegastes leucostictus and Malacoctenus macropus) were tested using only data from backreefs. All other fishes were analyzed using forereef data only.

The species of Assemblage 1 were recorded in diminishing numbers with depth, and this change was significant for all except Malacoctenus triangulatus and Acanthurus chirurgus. The 3 fishes of Assemblage 2 increased significantly in abundance with depth, as did Stegastes partitus and $S$. variabilis. Fishes in Assemblage 3 (S. leucostictus and M. macropus) showed no significant changes in abundance with depth on the backreef.

Therefore, it appears that Assemblage 1 was more abundant on the shallow forereef, whereas Assemblage 2 as well as Stegastes partitus and S. variabilis were more common in deeper areas of the forereef. Assemblage 3 dominated in the backreef. 
Table 2. Abundance and distributions of 14 fish species within 8 reefs near the southwest coast of Puerto Rico. Differences in numbers of individuals of each species occurring on forereefs compared with backreefs were determined using the Mann-Whitney $U$-test. Changes in fish abundance with depth were examined using the Kendall rank correlation coefficient. Tests of species in Assemblage 3 used data from backreefs only; all others utilized forereef data. Asterisks denote significant differences

\begin{tabular}{|c|c|c|c|c|}
\hline \multirow{2}{*}{\multicolumn{2}{|c|}{$\begin{array}{c}\text { Assemblage } \\
\text { number }\end{array}$}} & \multicolumn{2}{|c|}{$\begin{array}{c}\text { Density } \\
\text { (ind. } \mathrm{m}^{-2} \text { ) }\end{array}$} & \multirow{3}{*}{$\begin{array}{l}\text { Change in } \\
\text { abundance } \\
\text { with depth }\end{array}$} \\
\hline & & Forereef & f Backreef & \\
\hline 1 & Ophioblennius atlanticus & 0.48 & 0.19 & \\
\hline 1 & Stegastes dorsopunicans & 0.78 & $\cdots \quad 0.15$ & Decrease $\cdots$ \\
\hline 1 & Thalassoma bifasciatum & 1.61 & - $\quad 0.79$ & Decrease $\cdots$ \\
\hline 1 & Microspathodon chrysurus & 0.22 & 0.16 & Decrease ". \\
\hline 1 & Acanthurus coeruleus & 0.08 & 0.06 & Decrease.. \\
\hline 1 & Acanthurus chirurgus & 0.18 & 0.09 & Decrease \\
\hline 2 & Stegastes planifrons & 0.47 & $\cdots \quad 0.05$ & Increase $\cdots$ \\
\hline 2 & Hypoplectrus chlorurus & 0.05 & - $\quad 0.02$ & Increase $\cdots$ \\
\hline 2 & Holocentrus rufus & 0.08 & $\cdots \quad 0.02$ & Increase \\
\hline 3 & Stegastes leucostictus & 0.001 & $\cdots \quad 0.17$ & Increase \\
\hline 3 & Malacoctenus macropus & 0.01 & $\cdots \quad 0.15$ & Decrease \\
\hline- & Stegastes partitus & 0.12 & 0.06 & Increase $\cdots$ \\
\hline- & Stegastes variabilis & 0.04 & 0.02 & Increase $\cdots$ \\
\hline \multicolumn{5}{|c|}{${ }^{\circ} p<0.05, \cdots p<0.01, \cdots p<0.001$} \\
\hline
\end{tabular}

plot of species (Fig, 4B). Fishes of Assemblage 1, Ophioblennius atlanticus, Stegastes dorsopunicans, Thalassoma bifasciatum, Microspathodon chrysurus, Malacoctenus triangulatus, Acanthurus coeruleus, and A. chirugus, occurred within close proximity to each other near the left side of the species plot. This region of the ordination field corresponded to the area occupied, in general, by site Group 1 (offshore forereefs) in Fig. 4A.

Species in Assemblage 2, Stegastes planifrons, Hypoplectrus chlorurus, and Holocentrus rufus, were found in the lower right corner of the ordination field in Fig. 4B. This same area was occupied by nearshore forereefs (Group 3) in the DCA sites plot (Fig. 4A). S. partitus and $S$. variabilis occurred in ordination space between Assemblages $1 \& 2$ on the DCA species plot, and did not appear to be closely associated with either species group. The area occupied by $S$. partitus and $S$. variabilis corresponded to the

\section{Assemblage ordination}

Each stratum at each reef was treated as a site. Numbers of each species at each site were analyzed by DCA. Eigenvalues for DCA Axes 1, 2, 3, and 4 were $0.66,0.16,0.05$, and 0.04 , respectively. Square roots of eigenvalues $(0.81,0.40,0.22$, and 0.20 , respectively) estimated correlation coefficients between sets of DCA scores for species and samples. A higher correlation indicates stronger correspondence between sites and species, suggesting a more meaningful pattern. DCA Axes 3 and 4 were therefore relatively uninformative, and I concentrated on interpretation of Axes 1 and 2 .

A DCA plot of sites is presented in Fig. 4A. In this plot, sites were divided into the following 4 groups according to location on reefs: (1) forereefs of offshore reefs, (2) forereefs of intermediate reefs plus backreef of the submerged reef, (3) forereefs of nearshore reefs, and (4) backreefs of emergent reefs. This latter group occurred in the upper half of the ordination field, while the remaining 3 groups occupied the lower portion. Group 1 was on the left side of the field, and Group 3 was to the right, with Group 2 between and overlapping them. Reef 4 was the only reef in which both forereef and backreef strata fell together in a group in the lower half of the ordination field, indicating that there was relatively little variation between the 2 sides of the submerged reef.

The species associations indicated by the cluster analysis were used to delineate groups on the DCA region occupied by nearshore and deep intermediate forereefs in the DCA sites plot.

Assemblage 3 fishes, Stegastes leucostictus and Malacoctenus macropus, appeared in the upper half of the species plot. On the sites plot, this region was occupied solely by emergent backreefs.

Fishes of Assemblages 1 \& 2, therefore, displayed contrasting trends in their distributions. Although organisms in both assemblages were more common on forereefs than on backreefs, species in Assemblage 1 tended to decrease in number with depth and were more abundant on offshore reefs than nearshore reefs. Conversely, Assemblage 2 species tended to become more abundant with depth and were more common on nearshore reefs. Species of Assemblage 3 resided almost exclusively in the backreefs of emergent sites.

\section{Water movement}

Within reefs, significant differences were evident in water movement energy (as estimated by the degree of dissolution of plaster blocks) between forereefs and backreefs at all sites (Table 3). At offshore and intermediate emergent sites, water movement on the shallow forereef was significantly greater than on the backreef; intermediate values were recorded on the deep forereef which did not differ for other stations at these sites. At nearshore sites and the submerged reef, shallow forereef and backreef values for water motion 
did not differ from each other, and the deep forereef produced the lowest values.

Water motion also differed significantly among reefs (Table 4). When the forereefs of all 8 sites were ranked from smallest to largest by the median value for water movement, the offshore reefs had the highest degree of water motion energy, and the nearshore reefs had significantly less. Moderate values were recorded at the intermediate reefs. There was a significant difference in water motion among backreefs as well. The intermediate emergent reefs displayed the lowest values and the submerged reef the highest value.

\section{Depth profile}

Depth profiles of reefs were measured using width (in meters) of each stratum (i.e. length of the transect line from one meter's isobath to the next). Width served as a measurement of slope, or the amount of change in depth with distance from the reef. Smaller width indicated steeper reef slope. Depth profiles differed between forereefs and backreefs (Table 5); forereefs had significantly steeper slopes than backreefs. On forereefs, slope became steeper (i.e., stratum width became shorter) with depth (Table 5). On backreefs, width increased with depth, indicating that slope inclination decreased.

Stratum widths differed significantly among reefs (Table 6 ). On both forereefs and backreefs, the 3 emergent offshore reefs $(1,2 \& 3)$ had slopes with the greatest stratum widths (least inclination). The submerged reef (4) and the 2 nearshore reefs ( $7 \& 8$ ) had significantly steeper slopes (greater inclination).

\section{Substrate}

Of the 4 categories of substrate sizes (boulder, cobble, pebble and sand), all but pebble differed in distribution between forereefs and backreefs (Table 5). Boulder and cobble were more abundant on forereefs, and there was more sand on backreefs. On forereefs, the amount of boulder and cobble decreased with depth while the abundance of finer particles increased (Table 5). On backreefs, the abundance of sand increased with depth while the larger particles decreased with depth (although this result was not significant for boulders).

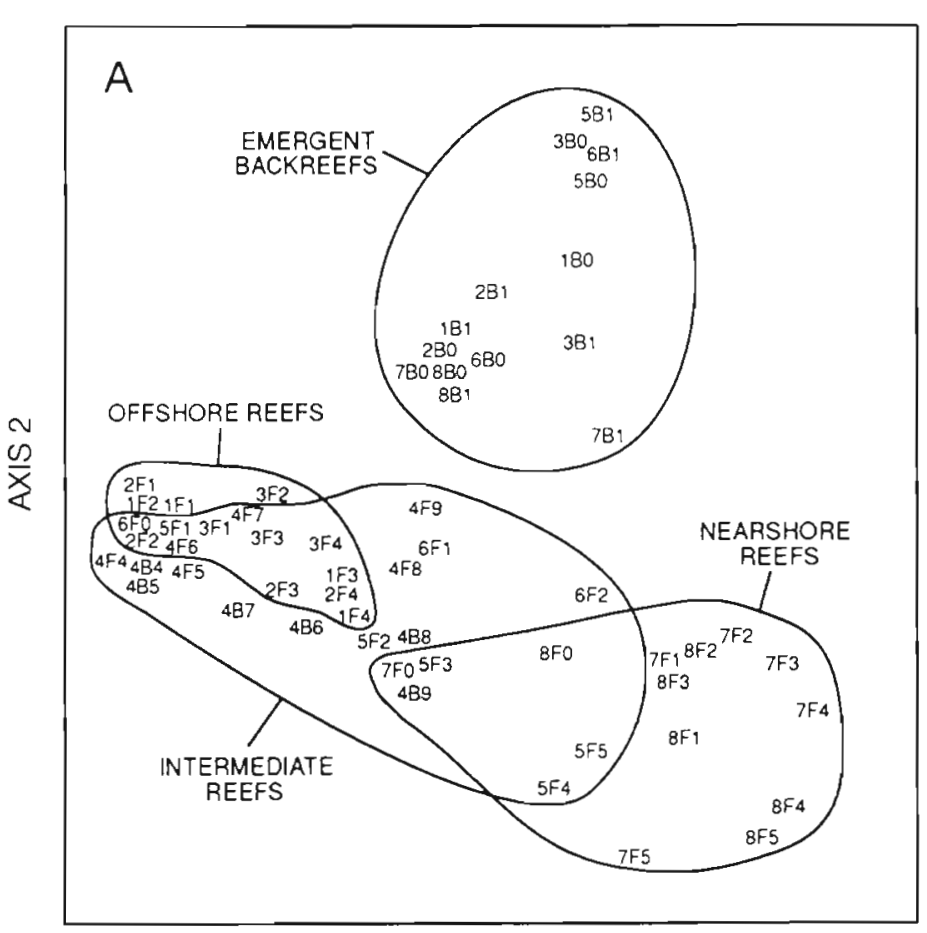

AXIS 1

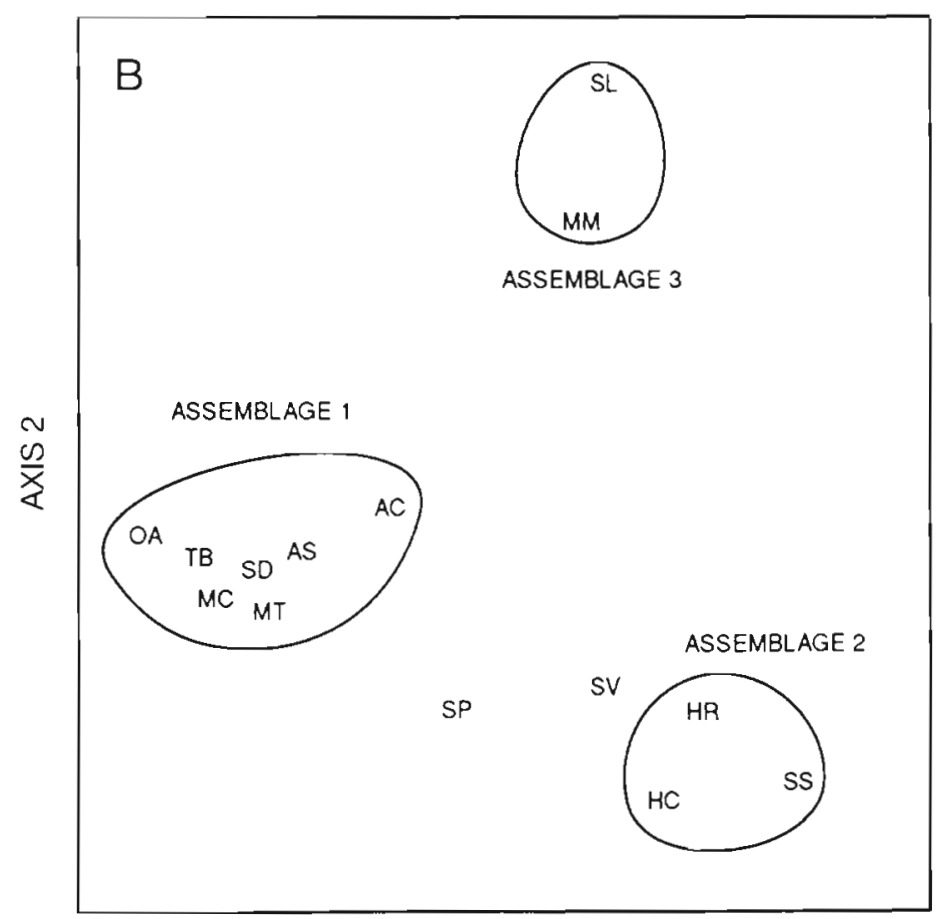

AXIS 1

Fig. 4. Plots of scores on the first 2 DCA axes for 58 sites at 8 coral reefs censused for fishes. (A) Scores for all 58 sites. Each site is a depth stratum represented by a 3-character code: the first digit indicates reef number, F or B indicates forereef or backreef, respectively. and the last digit identifies depth in meters (e.g. 5FO is the depth stratum between 0 and $1 \mathrm{~m}$ on the forereef of Reef S). (B) Scores for 14 fish species. Species codes as in Fig. 3 
Table 3. Comparison of differences in water movement estimated by dissolution of plaster blocks at stations within each of 8 reefs near the southwest coast of Puerto Rico. Numbers associated with $F$ (forereef) and $B$ (backreef) refer to depth in meters. Reef 6 included only 2 stations and was analyzed by Mann-Whitney $U$-test; all other reefs included 3 or 4 stations and were analyzed using Dunn's multiple comparisons based on Kruskal-Wallis rank sums. Stations are ranked from smallest to largest median value for water movement. Values connected by the same line are not significantly different at $p=0.05$

\begin{tabular}{|c|c|c|c|c|}
\hline Reef & \multicolumn{4}{|c|}{ Station } \\
\hline 1 & $1 \mathrm{~B}$ & $4 \mathrm{~F}$ & $1 \mathrm{~F}$ & \\
\hline 2 & $1 \mathrm{~B}$ & $4 \mathrm{~F}$ & $1 \mathrm{~F}$ & \\
\hline 3 & $1 \mathrm{~B}$ & $4 \mathrm{~F}$ & $1 \mathrm{~F}$ & \\
\hline 4 & $7 \mathrm{~F}$ & $7 \mathrm{~B}$ & $4 \mathrm{~B}$ & $4 \mathrm{~F}$ \\
\hline 5 & $1 \mathrm{~B}$ & $4 \mathrm{~F}$ & $1 \mathrm{~F}$ & \\
\hline 6 & $1 \mathrm{~B}$ & $1 \mathrm{~F}$ & & \\
\hline 7 & $4 \mathrm{~F}$ & $1 \mathrm{~B}$ & $1 \mathrm{~F}$ & \\
\hline 8 & $4 \mathrm{~F}$ & $1 F$ & $1 \mathrm{~B}$ & \\
\hline
\end{tabular}

Among all sites, the submerged reef (4) occupied the extremes in having the greatest abundance of boulder and least amount of other substrate types (Table 7 ). Among emergent forereefs, the 2 nearshore reefs $(7 \&$ 8) were among the groups with the least amount of boulder and the greatest abundance of finer substrates (pebble and sand). On backreefs, the submerged reef (4) represented one extreme as previously indicated; Reefs $5 \& 6$ both had the least amount of boulder and the greatest abundance of sand. These results were similar to the extremes illustrated in the analyses of water motion of backreefs and, to a lesser extent, forereefs (Table 4).

\section{Identification of ordination axes}

Data sets for water motion, depth profiles, and substrate sizes were each divided into 2 groups representing high and low values which were superimposed on plots of DCA site scores. A gradient of water motion was evident along Axis 1 (Fig. 5A); sites with a high degree of water movement were congregated on the left, and those with relatively low movement were on the right side of the ordination field. Similarly, a substrate size gradient also was apparent on Axis 1. Sites containing
Table 4. Comparison of water movement values measured by dissolution of plaster blocks at stations among 8 reefs near the southwest coast of Puerto Rico using Dunn's multiple comparisons based on Kruskal-Wallis rank sums. Reefs are ranked from smallest to largest median value for water movement. Values connected by the same line are not significantly different at $p=0.05$

\begin{tabular}{|llllllllll|}
\hline & \multicolumn{8}{c|}{ Reef number } \\
Forereefs & 8 & 7 & 4 & 5 & 6 & 2 & 3 & 1 \\
\cline { 2 - 9 } Backreefs & 6 & 5 & 3 & 7 & 8 & 1 & 2 & 4 \\
\hline
\end{tabular}

greater than $50 \%$ boulder per quadrat were mostly on the left half of the field, and those dominated by the smallest substrate sizes (pebble and sand) were more common on the right side (Fig. 5B,C). A depth profile gradient was evident along Axis 2 (Fig. 5D). Sites with a steep slope appeared near the lower half of the ordination field, and those with a more gradual slope were found mostly in the upper portion.

\section{DISCUSSION}

Coral reefs have been repeatedly shown to be divided into zones which include different assemblages (reviewed by Russ 1984b). However, the number and type of zones and the species inhabiting them vary geographically as well as with the methodology and interpretation of results by the researchers. The present study identified 3 general zones within reefs with asso-

Table 5. Tests for differences in depth profiles and substrate sizes within and among 8 reefs near southwest Puerto Rico. Mann-Whitney $U$-test determined differences in quantities on forereefs versus backreefs. Kendall rank correlation coefficient tested for changes in quantities with depth. Depth profiles were measured per stratum; substrate types were measured per quadrat. Asterisks denote significant differences

\begin{tabular}{|c|c|c|c|c|}
\hline \multirow[t]{2}{*}{ Parameter } & \multicolumn{2}{|c|}{ Median } & \multicolumn{2}{|c|}{$\begin{array}{c}\text { Change in quantity } \\
\text { with depth }\end{array}$} \\
\hline & Forereef & Backreef & Forereef & Backreef $^{a}$ \\
\hline $\begin{array}{l}\text { Depth profile } \\
\text { (stratum width in } \mathrm{m} \text { ) }\end{array}$ & 8 & $\cdots$ & Decrease $\cdot$. & Increase $\cdot$. \\
\hline \multicolumn{5}{|c|}{ Substrate (cover in $\mathrm{cm}^{2}$ ) } \\
\hline Boulder & 39500 & $\cdots \quad 4500$ & Decrease.. & Decrease \\
\hline Cobble & 5500 & $\cdots \quad 0$ & Decrease $\cdots$ & Decrease \\
\hline Pebble & 2000 & 0 & Increase ${ }^{\circ}$ & Decrease'.. \\
\hline Sand & 3650 & $\cdots 24200$ & Increase $\cdots$ & Increase $"$ \\
\hline \multicolumn{5}{|c|}{$\begin{array}{l}{ }^{2} \text { The backreef of the submerged reef was eliminated from this analysis as } \\
\text { it differed significantly from emergent backreefs in substrate and depth } \\
\text { profile } \\
{ }_{p}<0.05, \cdots p<0.01, \cdots p<0.001\end{array}$} \\
\hline
\end{tabular}


Table 6. Results of Dunn's multiple comparisons based on Kruskal-Wallis rank sums for depth profiles which differed in distribution among 8 reefs near southwest Puerto Rico. Reefs are ranked from steepest to least inclined slopes. Values connected by the same line are not significantly different at $p=0.05$

\begin{tabular}{|llllllllll}
\hline & \multicolumn{8}{c}{ Reef number } \\
Forereefs & 4 & 7 & 8 & $\underline{5}$ & 6 & 1 & 2 & 3 \\
Backreefs & 4 & 7 & 8 & 6 & 5 & 1 & 2 & 3 \\
\cline { 2 - 8 }
\end{tabular}

ciated assemblages: shallow forereef, deep forereef and backreef. Emery (1973) divided coral reefs into 3 comparable zones, which he further subdivided into 17 areas. Others have described divisions into 4 (Jones 1968, Alevizon et al. 1985, Galzin \& Legendre 1987), 5 (Goldman \& Talbot 1976, Bell \& Galzin 1984, Russ 1984a, b), 7 (Van den Hoek et al. 1978, Harmelin-Vivien 1989) and 8 (Hiatt \& Strasburg 1960) major habitat zones. The reef communities indicated in some of these studies were not evident at the reefs in La Parguera, Puerto Rico. For example, the spur-and-groove zone and Acropora cervicornis zone common at reefs in other
Table 7. Results of Dunn's multiple comparisons based on Kruskal-Wallis rank sums for substrates which differed in distribution among forereefs and backreefs on 8 sites near southwest Puerto Rico. Reefs are ranked from least to greatest median coverage of each substrate type. Values connected by the same line are not significantly different at $p=0.05$

\begin{tabular}{|c|c|c|c|c|c|c|c|c|}
\hline & \multicolumn{8}{|c|}{ Reef number } \\
\hline \multicolumn{9}{|l|}{ Forereefs } \\
\hline Boulder & 8 & 3 & 7 & 2 & 5 & 1 & 6 & $\underline{4}$ \\
\hline Cobble & 4 & 6 & 7 & 1 & 2 & 8 & 5 & 3 \\
\hline Pebble & $\underline{4}$ & 3 & 5 & 6 & 1 & 2 & 8 & 7 \\
\hline Sand & $\underline{4}$ & 3 & 6 & 2 & 5 & 1 & 7 & 8 \\
\hline \multicolumn{9}{|l|}{ Backreefs } \\
\hline Boulder & 5 & 6 & 8 & 3 & 1 & 2 & 7 & 4 \\
\hline Cobble & 4 & 6 & 5 & 1 & 3 & 7 & 8 & 2 \\
\hline Pebble & $\underline{4}$ & 5 & 6 & $\underline{3}$ & 1 & 8 & 7 & 2 \\
\hline Sand & 4 & 2 & 7 & 1 & 3 & 8 & 6 & 5 \\
\hline
\end{tabular}

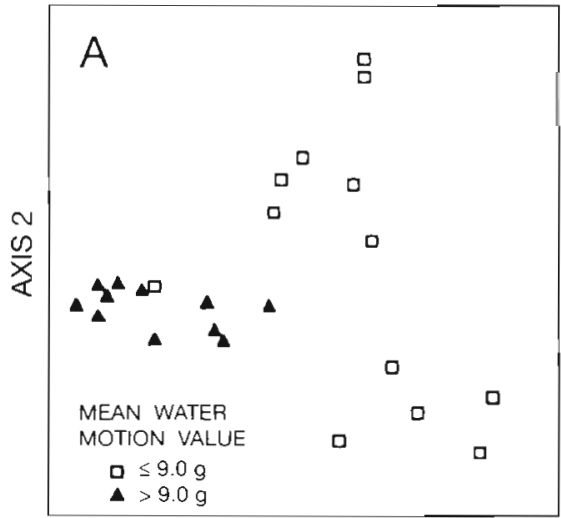

AXIS 1

Fig. 5. Environmental information superimposed on plots of scores on the first 2 DCA axes for 58 sites at 8 coral reefs censused for fishes. (A) Site scores plotted by water motion. The data set was divided according to the mean weight dissolved from plaster blocks by water movement. Higher values indicate greater water motion. (B \& C) Site scores plotted by substrate particle sizes. Boulder is the largest size, pebble and sand the smallest. (D) Site scores plotted by depth profile, measured as median width of depth strata. Smaller widths indicate steeper reef slopes

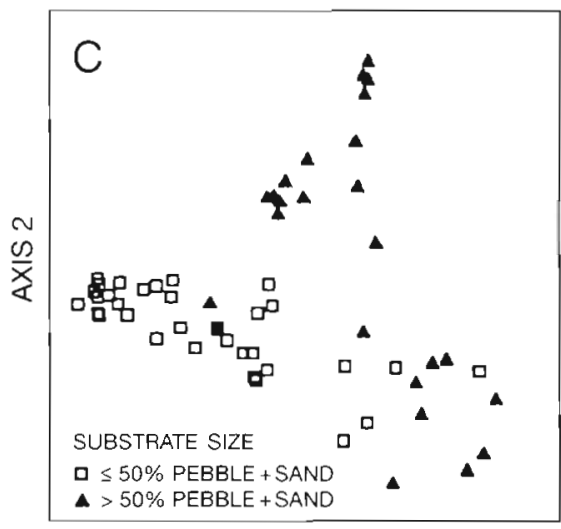

AXIS 1

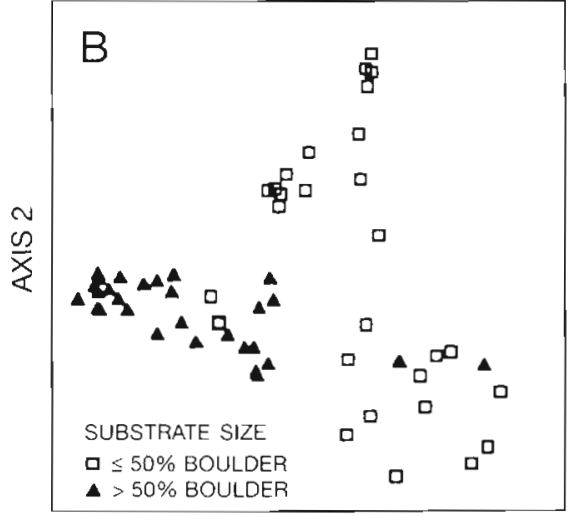

AXIS 1

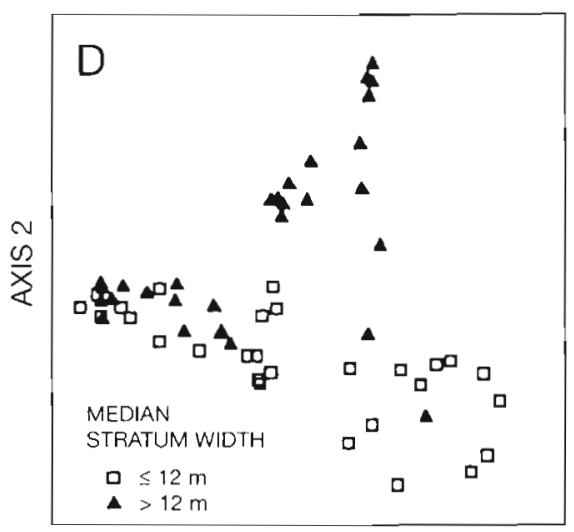

AXIS 1 
geographic areas (Goreau 1959) appeared in Parguera as patches at some sites and were totally absent from others. The divisions into shallow forereef, deep forereef and backreef are generalized zones which most reefs appear to have in common.

At the Parguera reefs, the shallow forereef varied in depth from the reef crest to about 2 to $4 \mathrm{~m}$ below the crest, depending on the individual reef. The deep forereef zone occurred below the shallow one and was sampled to a maximum of $10 \mathrm{~m}$, although it may have extended below that depth. In general, the charac. teristics of the shallow forereef included high water movement energy, large-sized substrates and an abundance of species in Assemblage 1 (Ophioblennius atlanticus, Stegastes dorsopunicans, Thalassoma bifasciatum, Microspathodon chrysurus, Malacoctenus triangulatus, Acanthurus coeruleus, and A. chirugus). In contrast, the deep forereef was typified by a moderate degree of water motion and substrates formed of more fine-particle sediments. Slope became steeper with depth on the forereef. Species in Assemblage 2 (S. planifrons, Hypoplectrus chlorurus, and Holocentrus rufus) were more common in the deep forereef zone than elsewhere. Although $S$. partitus and $S$. variabilis were not allied with other species groups, they appeared to occur in habitats more closely associated with Assemblage 2, suggesting the possibility of slight differences in habitat preference (McGehee 1991).

At emergent sites, the backreef was characteristically shallow (gentle slope) with little water movement, and predominantly sandy substrate. Fishes in Assemblage 3 (Stegastes leucostictus and Malacoctenus macropus) were found almost exclusively in this environment. Backreef characteristics differed dramatically between submerged and emergent reefs. The back of the submerged reef displayed physical and biological characteristics very similar to forereefs and had little in common with the backreefs at emergent sites, including a dearth or absence of Assemblage 3 fishes. Water movement, substrate particle sizes and steepness of slope were all greater at the submerged backreef than at emergent ones. The reef crest at emergent sites acts as an energy barrier at the surface between the forereef and backreef environments (Lugo 1982). Thus, the low water movement energy typical of backreefs at emergent sites was not evident at the submerged reef. Water could pass over and around a submerged site with relatively little difference in water motion between sides, allowing the formation of substrate and biota on the backreef similar to that found on the forereefs. Similarly, Ott (1975) reported that diversity patterns were nearly identical on inner and outer slopes at a submerged reef in Barbados. These findings suggest the significance of water motion in the community structure of coral reefs.
Other variables are influenced by water movement. Water motion (e.g. current or wave surge) has been identified as a major force responsible for sorting sediments in the marine environment (Friedman \& Saunders 1978). Wave energy at substrate level decreases with depth (Huston 1985). A high degree of water movement, as is found in the surge zone of the shallow forereef, suspends most small-sized particles and carries them away, leaving mainly the larger substrates (boulder and cobble); the abundance of fine particles increases seaward of the reef as water motion near the substrate decreases with depth and smaller sediments fall out of suspension (James 1983). Largesize substrates still exist in the deep forereef, but they tend to appear as outcrops (often covered with living organisms) surrounded by sand; a similar topography can be found in the backreef environment (Goreau \& Goreau 1973).

The amount of substrate affected by wave energy is related to steepness of slope (Denny 1988); sites with a steep slope have a proportionately smaller area of forereef exposed to strong wave surge than do those with a less inclined forereef. Changes in the abundance or type of sediment deposits can result in local alterations in depth or inclination of slope, with concomitant changes in surge, and vice versa. Therefore, water movement, depth and substrate are interdependent physical variables, affecting each other as well as the abundance and distribution of aquatic organisms.

Of the factors considered above, my results suggested that water movement exerted the most influence on other physical and biological variables, although it should not be considered separately from depth and substrate factors. Reports from the literature vary in their conclusions about the relative importance of these factors. Several other studies of coral reefs support my investigation in recognizing the importance of currents or wave action and associations of different assemblages of fishes with areas of differing hydrodynamic activity (Hiatt \& Strasburg 1960, Jones 1968, Hobson 1974, Galzin \& Legendre 1987). However, other researchers considered the distributions of reef fishes, as well as species richness and/or diversity, to be a function of substrate and shelter characteristics (e.g. Risk 1972, Emery 1973, Clarke 1977, Itzkowitz 1977, Luckhurst \& Luckhurst 1978, Gladfelter et al. 1980, Waldner \& Robertson 1980, Bell \& Galzin 1984. Shulman 1985, Roberts \& Ormond 1987, Hixon \& Beets 1993). Wellington (1982) indicated the importance of depth-related gradients in substrate complexity, whereas Alevizon et al. (1985) suggested that the influence of depth on habitat structure was subordinate to other factors. A few investigations, like the present study, have indicated that these variables are 
interrelated, affecting each other as well as fish species distributions on coral reefs (Waldner 1980, Bradbury \& Young 1981, Williams 1982, 1991, Russ 1984a, b).

Water movement, depth and substrate clearly vary within reefs, but the present study also demonstrated that they differ among reefs. Offshore reefs, those located farthest from the mainland and which received the greatest exposure to wind and currents, had forereefs characterized by greater water movement, less slope inclination and larger substrate sizes than nearshore reefs. Simiiarly, the abundance and distribution of species in the assemblages changed as one moved from offshore to nearshore reefs. A pattern of cross-shelf variation has been identified also at Australia's Great Barrier Reef (Done 1982, Williams 1982, 1991, Williams \& Hatcher 1983, Russ 1984a, b, Bradbury et al. 1986) and in Puerto Rico (Morelock et al. 1977, Kimmel 1985).

The dynamics of the interrelated variables of water motion, depth and substrate, and their effects on the biota throughout the reef system, can be demonstrated by focusing on the distributions of Assemblages $1 \& 2$. Species in Assemblage 1 were most common in the surge zone, the shallow area of the forereef typified by a high degree of water movement and boulder-sized substrate, factors which were particularly prevalent at the offshore reefs. Assemblage 2 species were more abundant in areas with the opposite characteristics. The distributions of the 2 assemblages and their associated variables tended to overlap on the forereef to varying degrees.

The area of overlap between Assemblages 1 \& 2 apparently shifts up or down the forereef slope according to the location of the reef. The shallow forereef zone is much wider at offshore reefs than nearshore ones, due largely to the difference in slope inclination and exposure to water movement energy. At offshore sites, waves impact the substrate at greater depth and distance seaward of the reef crest than at nearshore reefs. Consequently, Assemblage 1 expands in abundance and distribution to deeper waters at the highexposure offshore reefs. Assemblage 2 would be found even deeper, mostly below Assemblage 1. At nearshore reefs, the opposite would occur. Additionally, the width of the transition area between Assemblages 1 $\& 2$ is likely to vary. The gentle slopes of offshore reefs would allow a wider, less defined, transition area than would be expected on the steep slopes of nearshore reefs.

At nearshore sites, the transition between assemblages appears to occur higher up on the forereef. Assemblage 2 is more abundant and has spread up into shallower areas at nearshore sites, and the shallow forereef zone with Assemblage 1 occupies only a narrow stratum in the shallowest portion of nearshore reefs. This pattern can be seen in its extreme at the reef nearest to shore, Reef 8 ; members of Assemblage 1 were poorly represented and the majority were confined to the uppermost meter of depth. Some of the fishes included in Assemblage 1 (specifically, Ophioblennius atlanticus and Thalassoma bifasciatum) were never observed at Reef 8 . Studies by Done (1982) and Bradbury et al. (1986) suggest that this pattern is not unique to the Parguera study site; on Australia's Great Barrier Reef, the fauna on deep reef slope sites at an outer shelf reef was similar to that of shallower reef slope sites at a midshelf reef. Thus, it appears that water movement energy may have the same influence on the distribution and abundance of species in widely separated geographic locations.

Local topographic complexity, as well as biological variables, can influence or alter the predicted patterns. The presence of one reef zone type does not necessarily preclude the existence of characteristics associated with a different zone at the same location. Due to natural variability, for example, one may find deeper forereef habitat conditions within the shallow forereef zone. As a consequence, species composition and abundance are influenced, which may lead to local variations in species distributions

The present study does not conclude that the organisms identified in the assemblages were the only members of their respective groups or that they occurred only within the specified habitats. Members of the assemblages occasionally were found in areas other than those described for their groups, and alongside members of other assemblages. Additionally, it is likely that other species, either cryptic in nature or inadequately sampled, also should be included in the assemblages. As indicated earlier, biological variables must also be considered as an influence on fish community structure. However, the association of assemblages of coral reef fishes with gradients of water motion, depth and substrate has been demonstrated. This correspondence between biotic and abiotic variables suggests that it may be possible to predict which species are expected to occur in an area by measuring the physical factors, or vice versa.

Acknowledgements. I am grateful to D. Shapiro, D. Hensley, J. Wunderle, A. Lewis, D. Ballantine, R. Appeldoorn, C. Goenaga, and $M$. Reigle for their help and support in numerous ways. Many thanks go to P. Yoshioka for advice on statistics, to $\mathrm{S}$. Reed for her assistance underwater for hundreds of hours as dive partner, to D. Jones, G. Dennis, M. Ray, and F. Martinez for computer help, and to S. Bortone, D. Goulet, and J. Holmquist for reviews of the manuscript. Sea Grant project number R/LR-06-87-DSH2 and the Department of Marine Sciences of the University of Puerto Rico graciously made financial support and facilities available. 


\section{LITERATURE CITED}

Alevizon, W., Richardson, R., Pitts, P., Serviss, G. (1985). Coral zonation and patterns of community structure in Bahamian reef fishes. Bull. mar. Sci. 36: 304-318

Bell, J. D., Galzin, R. (1984). Influence of live coral cover on coral-reef fish communities. Mar. Ecol. Prog. Ser. 15: 265-274

Boesch, D. F. (1977). A new look at the zonation of benthos along the estuarine gradient. In: Coull, B. C. (ed.) Ecology of marine benthos. University of South Carolina Press, Columbia, p. 245-266

Bradbury, R. H., Loya, Y., Reichelt, R. E., Williams, W. T. (1986). Patterns in the structural typology of benthic communities on two coral reefs of the central Great Barrier Reef. Coral Reefs 4: 161-167

Bradbury, R. H., Young, P. C. (1981). The effects of a major forcing function, wave energy, on a coral reef ecosystem. Mar. Ecol. Prog. Ser. 5: 229-241

Buchanan, J. B., Kain, J. M. (1971). Measurement of the physical and chemical environment. In: Hoime, N. A., McIntyre, A. D. (eds.) Methods for the study of marine benthos. Blackwell Scientific Publications, Oxford, p. 30-58

Clarke, R. D. (1977). Habitat distribution and species diversity of chaetodontid and pomacentrid fishes near Bimini, Bahamas. Mar. Biol. 40:277-289

Dana, T. F. (1976). Reef-coral dispersion patterns and environmental variables on a Caribbean coral reef. Bull. mar. Sci. 26: $1-13$

Denny, M. W. (1988). Biology and the mechanics of the waveswept environment. Princeton University Press, Princeton

Done, T. J. (1982). Patterns in the distribution of coral communities across the central Great Barrier Reef. Coral Reefs 1: 95-107

Doty, M. S. (1971). Measurement of water movement in reference to benthic algal growth. Botanica mar. 14:32-35

Emery, A. R. (1973). Comparative ecology and functional osteology of fourteen species of damselfish (Pisces: Pomacentridae) at Alligator Reef, Florida Keys. Bull. mar. Sci. 23: $649-770$

Friedman, G. M., Saunders, J F. (1978). Principles of sedimentology. John Wiley, New York

Galzin, R., Legendre, P. (1987). The fish communities of a coral reef transect. Pacif. Sci. 41: 158-165

Gauch, H. G. (1982). Multivariate analysis in community ecology. Cambridge Univ. Press, Cambridge

Gladfelter, W. B., Ogden, J. C., Gladfelter, E. H. (1980). Similarity and diversity among coral reef fish communities: a comparison between tropical western Atlantic (Virgin Islands) and tropical central Pacific (Marshall Islands) patch reefs. Ecology 61. 1156-1168

Goldman, B., Talbot, F. H. (1976). Aspects of the ecology of coral reef fishes. In: Jones, O. A., Endean, R. (eds.) Biology and geology of coral reefs, Vol 3, Biology, Part 2. Academic Press, New York, p. 125-154

Goreau, T. F. (1959). The ecology of Jamaican reefs. I. Species composition and zonation. Ecology 40:67-90

Goreau, T. F., Goreau, N. I. (1973). The ecology of Jamaican coral reefs. II. Geomorphology, zonation, and sedimentary phases. Bull. mar. Sci. 23: 399-464

Gorman, O. T., Karr, J. K. (1978). Habitat structure and streamfish communities. Ecology 59: 507-515

Green, D. G., Bradbury, R. H., Reichelt, R. E. (1987). Patterns of predictability in coral reef community structure. Coral Reefs $6: 27-34$

Harmelin-Vivien, M. L. (1989). Reef fish community structure: an Indo-Pacific comparison. In: Harmelin-Vivien, M. L.,
Bourliere, F. (eds.) Ecological studies, Vol. 69. Vertebrates in complex tropical systems. Springer-Verlag, New York, p. $21-60$

Hiatt, R. W., Strasburg, D. W. (1960). Ecological relationships of the fish fauna on coral reefs of the Marshall Islands. Ecol. Monogr. 30: 65-127

Hixon, M. A., Beets, J. P. (1993). Predation, prey refuges, and the structure of coral-reef assemblages. Ecol. Monogr. 63: $77-101$

Hobson, E. S. (1974). Feeding relationships of teleostean fishes on coral reefs at Kona, Hawaii. Fish. Bull. U.S. 72: 915-1031

Huston, M. A. (1985). Patterns of species diversity on coral reefs. A. Rev. Ecol. Syst. 16: 149-177

Itzkowitz, M. (1977). Spatial organization of the Jamaican damselfish community. J. exp. mar. Biol. Ecol. 28: 217-242

James, N. P. (1983). Reef environment. In: Scholle, P. A., Bebour, D. G., Moore, C. H. (eds.) Carbonate depositional environments. Memoir 33, American Association of Petroleum Geologists, Tulsa, OK, p. 345-462

Jones, R. S. (1968). Ecological relationships in Hawaiian and Johnston Island Acanthuridae (surgeonfishes). Micronesica 4: 309-361

Kimmel, J. J. (1985). A characterization of Puerto Rican fish assemblages. Ph.D. thesis, Univ. of Puerto Rico, Mayaguez

Luckhurst, B. E., Luckhurst, K. (1978). Analysis of the influence of substrate variables on coral reef communities. Mar. Biol. 49: 317-323

Lugo, A. (1982). Wave energy distribution of Margarita Reef, southwestern Puerto Rico. M.Sc. thesis, Univ. of Puerto Rico, Mayaguez

McGehee, M. A. (1991). Distributions of fish species assemblages within and among coral reefs. Ph.D. thesis, Univ. of Puerto Rico, Mayaguez

McGehee, M. A. (1992). Distribution and abundance of two species of Echinometra (Echinoidea) on coral reefs near Puerto Rico. Caribb. J. Sci. 28: 173-183

Morelock, J., Schneidermann, N., Bryant, W. R. (1977). Shelf reefs, southwestern Puerto Rico. In: Frost, S. H., Weiss, M. P. Saunders, J. B. (eds.) Reefs and related carbonates - ecology and sedimentology. American Association of Petroleum Geologists, Tulsa, OK, p. 17-25

Ott, B. (1975). Community patterns on a submerged barrier reef at Barbados. West Indies. Int. Rev. ges. Hydrobiol. 60: $719-736$

Pimentel, R. A., Smith, J. D. (1986). BIOETAT II. A multivariate statistical toolbox. Sigma Soft, Placentia, CA

Rakocinski, C. F., Baltz, D. M., Fleeger, J. W. (1992). Correspondence between environmental gradients and the community structure of marsh-edge fishes in a Louisiana estuary. Mar. Ecol. Prog. Ser. 80: 135-148

Risk, M. J. (1972). Fish diversity on a coral reef in the Virgin Islands. Atoll Res. Bull. 153: 1-6

Roberts, C. M., Ormond, R. F. G. (1987). Habitat complexity and coral reef fish diversity and abundance on Red Sea fringing reefs. Mar. Ecol. Prog. Ser. 41: 1-8

Russ, G. (1984a). Distribution and abundance of herbivorous grazing fishes in the central Great Barrier Reef. I. Levels of variability across the entire continental shelf. Mar Ecol. Prog. Ser. 20: 23-34

Russ, G. (1984b). Distribution and abundance of herbivorous grazing fishes in the central Great Barrier Reef. II. Patterns of zonation of mid-shelf and outershelf reets. Mar Ecol. Prog. Ser. 20: 35-44

Sale, P. F. (ed.) (1991). The ecology of fishes on coral reefs. Academic Press, San Diego

Schlosser, I. J. (1982). Fish community structure and function 
along two habitat gradients in a headwater stream. Ecol. Monogr. 52: 395-414

Shulman, M. J. (1985). Recruitment of coral reef fishes: effects of distribution of predators and shelter. Ecology 66: $1056-1066$

Turingan, R. G., Acosta, A. B. (in press). The fish assemblages on a coral patch reef in Puerto Rico. Proc. Gulf Caribb. Fish. Inst. 43

Van den Hoek, C., Breeman, A. M., Bak, R. P. M., Van Buurt, G. (1978). The distribution of algae, corals and gorgonians in relation to depth, light attenuation, water movement and grazing pressure in the fringing coral reef of Curaçao, Netherlands Antilles. Aquat. Bot. 5: 1-46

Waldner, R. E. (1980). Aspects of coexistence in a guild of damselfishes (Pisces: Pomacentridae) off southwest Puerto Rico. Ph.D. thesis, Univ. of Puerto Rico, Mayaguez

Waldner, R. E., Robertson, R. (1980). Patterns of habitat partitioning by eight species of territorial Caribbean damselfishes (Pisces: Pomacentridae). Bull. mar. Sci. 30: $171-186$

This article was presented by K. L. Heck Jr, Dauphin Island, Alabama, USA
Weinstein, M. P., Weiss, S. L., Walters, M. F. (1980). Multiple determinants of community structure in shallow marsh habitats, Cape Fear River estuary, North Carolina. Mar. Biol. 58: 227-243

Wellington, G. M. (1982). Depth zonation of corals in the Gulf of Panama: control and facilitation by resident reef fishes. Ecol. Monogr. 52: 223-241

Whittaker, R. H. (1975). Communities and ecosystems, 2nd edn. MacMillan Publishing Co., New York

Williams, D. McB. (1982). Patterns in the distribution of fish communities across the central Great Barrier Reef. Coral Reefs 1: $35-43$

Williams, D. McB. (1991). Patterns and processes in the distribution of coral reef fishes. In: Sale, P. F. (ed.) The ecology of fishes on coral reefs. Academic Press, San Diego, p. $437-474$

Williams, D. McB., Hatcher, A. I. (1983). Structure of fish communities on outer slopes of inshore, mid-shelf and outer shelf reefs of the Great Barrier Reef. Mar. Ecol. Prog. Ser. 10: $239-250$

Manuscript first received: December 15, 1992 Revised version accepted: November 26, 1993 